\title{
Forecasting of an output of eco toxicants at thermal decomposition of chemical fuel
}

\author{
Olga Barysheva*, Renat Sadykov, Yuri Khabibullin and Elizaveta Zheltukhina
}

Kazan State University of Architecture and Engineering, Kazan, Russian Federation

\begin{abstract}
Combustion of high-energy chemical fuels containing chlorine in the element structure can lead to formation in the particles of smoke of super eco toxicants - the polychlorinated dioxins and furans. The numerical experiment conducted was based on solution of the equations of chemical kinetics. The computational and theoretical researches directed to the solution of a problem of determination of parameters of combustion products of chemical fuels taking into account formation of harbingers of the polychlorinated dioxins were executed. The main data on the accepted method of determination of disequilibrium structures of products of burning the chlorine-containing chemical fuels were represented. Based on the analysis of references about mechanisms and speeds of chemical reactions of transformations of chlorine-containing connections, the kinetic model of formation of predecessors of dioxins is constructed. The carried-out calculations showed (assuming chemical balance) that process of formation of dioxins is significantly disequilibrious. The results of kinetic researches on emission of harbingers of dioxins showed the nature of the influence of different components of combustion products of chemical fuels on time for the different levels of temperatures.
\end{abstract}

\section{Introduction}

Dioxins on particles of the smoke, which is formed at combustion of chemical fuels, is found nearly a quarter of the century back. However, despite numerous laboratory and natural researches there is no complete quantitative description of processes of integration and disintegration of the polychlorinated dioxins, furans, and biphenyls now. Concentration of the dioxins, which is formed at combustion of chemical fuels, are usually small, and the published results of researches have wide variation in the measured concentration. As formation of dioxins is only insignificant collateral reaction in the general process of decay and synthesis of organic compounds, interpretation of experimental results is difficult procedure in comparison with researches of the main reactionary process [1-3].

Establishment of distribution of chlorine atoms in dibenzene - $p$ - dioxins was important result of the analysis of composition of dioxins on smoke particles (the solid condensed particles). In most cases, stronger chlorinated connections are more preferably formed, and often the maximum of distribution corresponds six replacements with chlorine atoms of hydrogen atoms [4].

In certain cases preferable are oktochlorinated connections. Isomer 2, 3, 7, 8 - tetra chlorine dibenzene - $\mathrm{p}$ - dioxins is formed not in the largest quantity. There is no standard theoretical model of the mechanism of formation of dioxins reproducing observed distribution yet. It is connected in particular with complex set of the physical and chemical processes proceeding in combustion chambers for combustion of chemical fuels $[5,6]$.

Dioxins formation occurs in the temperature range of $500 \ldots 800 \mathrm{~K}$ [7]. In the presence of particles of smoke, chlorine and at excess of oxygen, many aromatic connections can form connections of type of dioxins with the corresponding distribution on family of the chlorine-replaced dioxins. The chlorinated phenols and the high-chlorinated aromatic esters can be the most probable harbingers. Experiments show that formation of dioxins the easiest happens in the presence of pentachlorophenol $\left(\mathrm{C}_{6} \mathrm{Cl}_{5} \mathrm{OH}\right)$ [8-10].

Low level of temperatures of formation of dioxins demands accounting of kinetic factors. Uncertainty as a part of reactionary mixture, in properties of particles of smoke, kinetics of pyrolysis and chemical stability of connections have a great influence on reliability of forecasting of emission of dioxins by methods of chemical kinetics under the considered conditions.

It is necessary for determination of the regime parameters providing the minimum exit of dioxins, reliable forecasting of structure and properties of products of chemical fuels [11]. The solution of an objective demands attraction of the advanced methods and the latest developments of many sciences: chemical kinetics and thermodynamics, gas dynamics and heat exchange, kinetics of phase transformations, molecular and kinetic theory of gases and liquids. It is connected with the fact that real process of combustion of chemical fuels represents the difficult process which is carried out in the wide range of temperature, times of stay in

* Corresponding author: obbars@ gmail.com 
reaction and includes a large amount of various substances [12,13]. With oxidizing reactions also pyrolytic can proceed. The description of evolution in time of various substances requires reliable definition of entry conditions that often cannot be made. The problem is complicated also by the fact that now there is no complete quantitative description of education and disintegration of dioxins [14]. The published experimental results often have significant variation in concentration of dioxins. Perhaps, it is connected with the fact that formation of dioxins is only insignificant collateral reaction in the general process of disintegration of organic matter. In this regard, based on the available experimental data it is difficult reliable to present the mechanism of chemical reactions, constants of speeds of these reactions.

Measurement of concentration of various products of combustion on a path of propulsion or power stations indicates formation of more and more chlorinated substances, when sampling in the direction from an exit from the combustion chamber to output section. From here, it is possible to draw a conclusion that the majority of dioxins is formed consistently with process of burning or in heat exchangers. The role of the combustion chamber consists in delivery of molecules - harbingers of formation of dioxins. Defining conditions for minimization of processes of formation of these harbingers, it is possible to limit to that and emission of dioxins [15-17].

Calculations showed in an assumption of chemical balance that thermodynamic barriers to disintegration of dioxins, furans, biphenyls at temperatures characteristic of burning of chemical fuels ( $T>1400 \mathrm{~K})$ do not exist. At sufficient time of stay in the chemical reactor (combustion chamber) and excess of oxygen, it is always possible to spread out dioxins and any other organic compounds. It indicates the prevailing influence of kinetic factors [18-20].

The models of processes of formation of harbingers of dioxins based on concepts of chemical thermodynamics and formal chemical kinetics and separate calculation results on the developed models and algorithms were considered.

\section{Method of calculation of parameters of disequilibrium burning of chemical fuels}

\subsection{Disequilibrium change of composition of combustion products}

For the majority of units in which processes proceed at high temperature different disequilibrium effects are peculiar. The most important of them is the disequilibrium change of composition of combustion products, heating or decomposition caused by final speeds of the proceeding chemical reactions resulting in significant effect on the key power parameters of process [21].
These processes are described within formal chemical kinetics and consist in determination of structure of a working body on the set mechanism and constants of speeds of reactions. Is accepted that all transformations in a gas phase are elementary, i.e. proceed in one stage. Any chemical interactions can be provided by set of these elementary stages. In work, the method of the solution of the equations of chemical kinetics described in a source was accepted [21-23].

\subsection{Statement and solution of the problem}

Main objective of an objective is the numerical experiment for forecasting of education and decomposition of the chlorine-containing hydrocarbons which are harbingers of dibenzene dioxins in thermal power stations; forecasting of concentration of the received connections, the temperature range and pressure characteristic of the maximum concentration of the considered connections.

In this experiment, the process of decomposition $\mathrm{C}_{6} \mathrm{H}_{5} \mathrm{Cl}$ (chlorobenzene) was predicted.

Schemes of the models developed for carrying out numerical experiments are presented on fig. 1. In the first experiment, the system of flowing non-stationary reactors 1-4 of ideal mixing is considered. In the first reactor methane is brought (methane with mass flow equal $G=0.1 \mathrm{~kg} / \mathrm{sec}$ ) + air (with mass flow $G=1.72$ $\mathrm{kg} / \mathrm{sec}$ ), at stoichiometric ratio of components (coefficient of excess of oxidizer $\alpha=1$ ). Pressure in the reactor of $1 \mathrm{~atm}$. On mass flows methane + air and time of stay of mixture in the reactor is timed $\tau=V \rho / G=5 \ldots 10 \mathrm{~m} / \mathrm{sec}$, what corresponds to reactor volume $V=0.05 \ldots 0.1 \mathrm{~m}^{3}$. We accept volume value $V=0.08 \mathrm{~m}^{3}$.

Result of integration of a system of equations of chemical kinetics in this reactor chemically equilibrium structure is set.

In the second flowing reactor we reduce mixture temperature due to withdrawal of heat $Q, \mathrm{~kJ} / \mathrm{sec}: 3400-$ at $T=1000 \mathrm{~K}, 3200-$ at $T=1100 \mathrm{~K}, 3000-$ at $T=1200 \mathrm{~K}$, $2800-$ at $T=1300 \mathrm{~K}, 2500-$ at $T=1400 \mathrm{~K}$ to receive the temperature range of destructive conversions of chlorobenzene, characteristic of processes.

In the third flowing reactor chlorobenzene with different mass fractions moves: $g_{1}=0.0001(0.01 \%)$; $g_{2}=0.01(1 \%)$ from total amount of mix.

In the fourth reactor, for chlorobenzene decomposition process consideration, the multicomponent structure is considered.

In the second experiment, the supply to group of flowing reactors of mixture of combustion products is made (methane+air at $\alpha=1$ ) and the products of decomposition containing chlorine-containing connections (chlorobenzene $\mathrm{C}_{6} \mathrm{H}_{5} \mathrm{Cl}$, tetrachloroethylene $\mathrm{C}_{2} \mathrm{Cl}_{4}$ etc.). In this case, the model structure of products of decomposition was accepted typical for model fuels. 

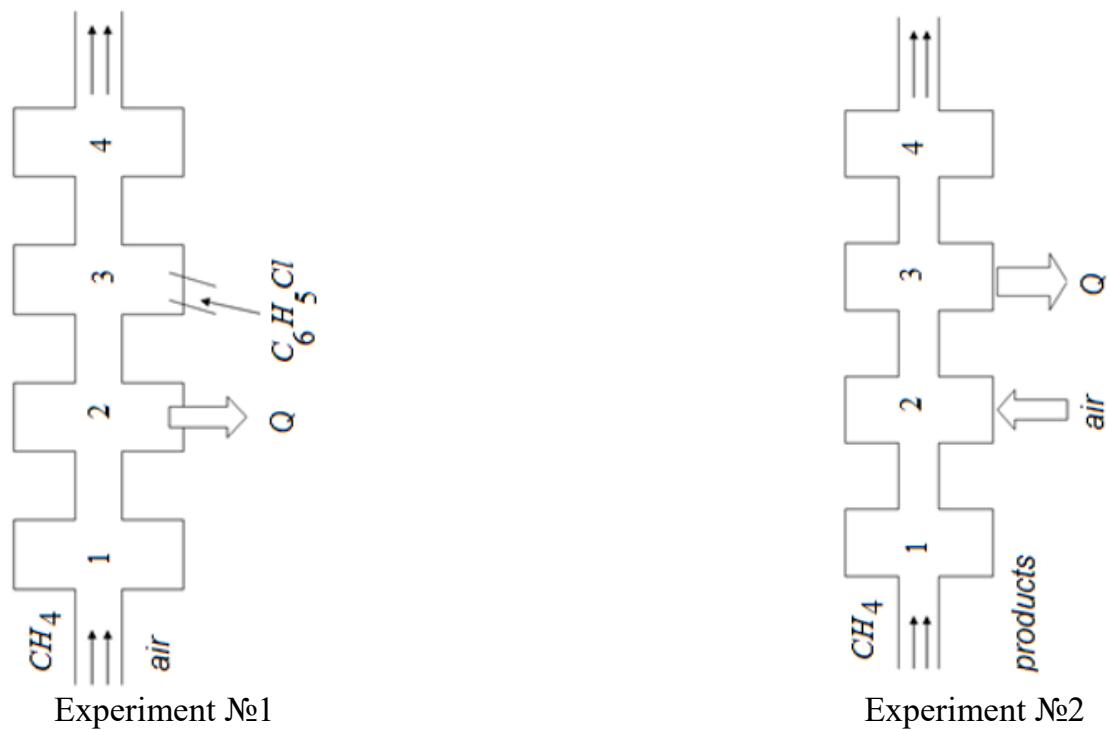

Experiment №2

Fig. 1. The scheme of a mathematical model for carrying out a numerical experiment: 1,2, 3, 4 - flowing non-stationary reactors.

\section{Results and Discussion}

Results of the conducted computing researches on the first model are presented in fig. 2-9.

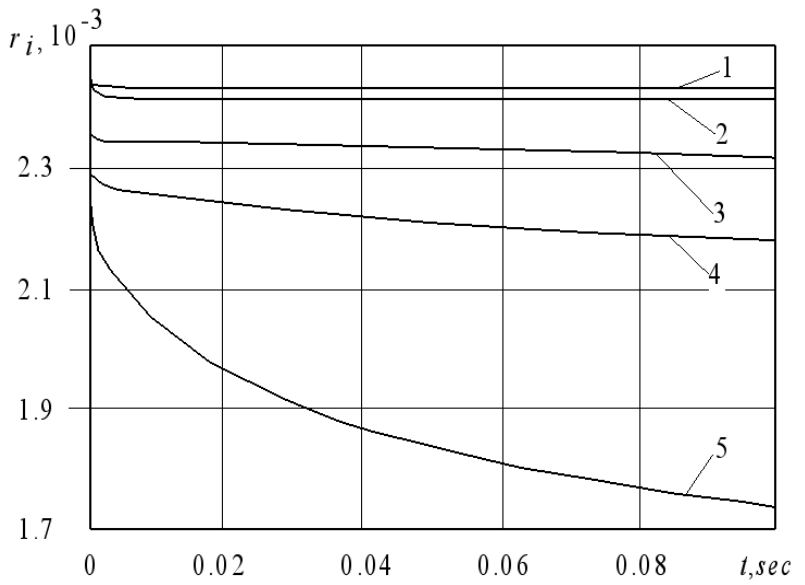

Fig. 2. Change of a mole dole of chlorobenzene at a mass fraction $g=0.01$ from composition of mixture and various reference temperatures: $1-1000 \mathrm{~K} ; 2-1100 \mathrm{~K} ; 3-1200 \mathrm{~K}$; 4$1300 \mathrm{~K} ; 5-1400 \mathrm{~K}$

When reference temperature is equal $1000 \mathrm{~K}$ the character of change of a curve rectilinear. At a mass fraction of chlorobenzene $g=0.01$ its structure slightly falls in the beginning at $T \leq 1100 \ldots 1200 \mathrm{~K}$, and then it is stabilized. At $T \geq 1300 \mathrm{~K}$ at first concentration of chlorobenzene sharply falls, and then monotonously decreases on time (fig. 2).

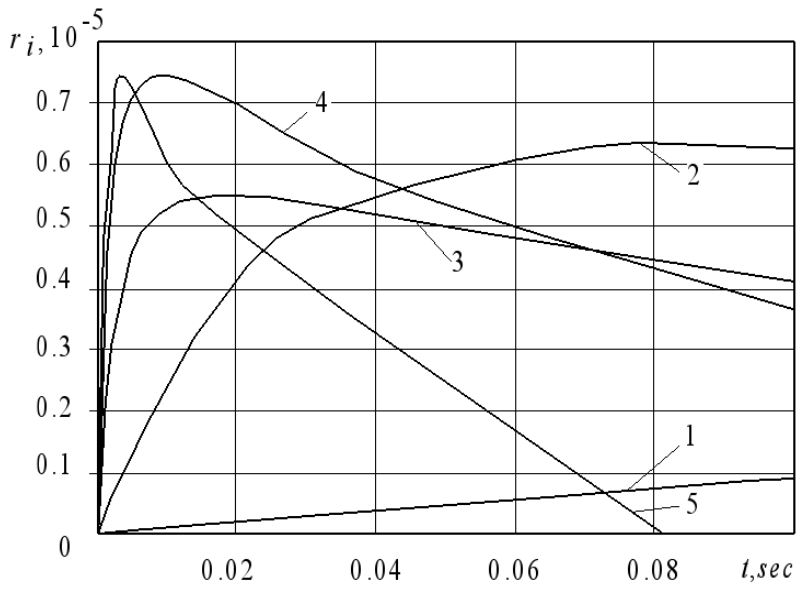

Fig. 3. Change of a mole dole dichlorobenzene at a mass fraction of chlorobenzene $g=0.0001$ from composition of mixture and various reference temperatures: $1-1000 \mathrm{~K} ; 2$ $1100 \mathrm{~K} ; 3-1200 \mathrm{~K} ; 4-1300 \mathrm{~K} ; 5-1400 \mathrm{~K}$.

At a temperature above $1500 \mathrm{~K}$ dichlorobenzene $\mathrm{C}_{6} \mathrm{H}_{4} \mathrm{Cl}_{2}$ behaves ambiguously (fig. 3). At first process of chemical reaction goes with surge in concentration, but then beginning $0.005 \mathrm{sec}$. with there is a sharp decrease and having reached value 0.083 sec. about dichlorobenzene completely burns down. At temperatures, $1200 \ldots 1300 \mathrm{~K}$ similar process, but is dragged more out on time. At temperatures, $1100 \mathrm{~K}$ there is a sharp jump of concentration of dichlorobenzene, to the subsequent falling at the output. 


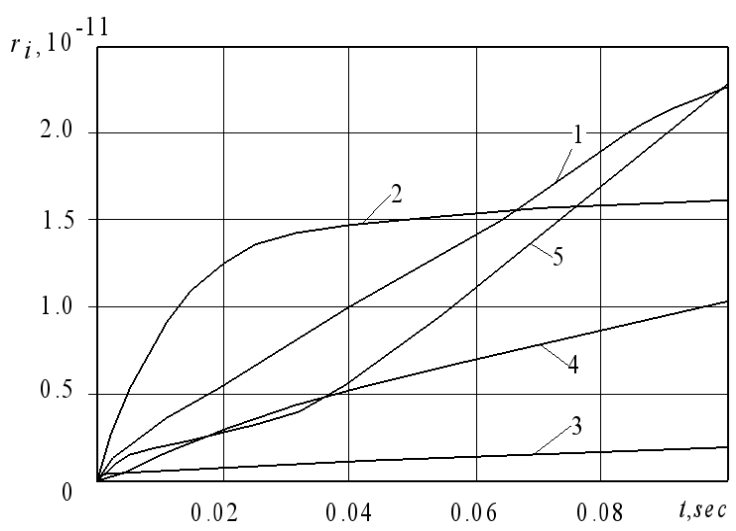

Fig. 4. Change of a mole dole chloromethane $\mathrm{CH}_{3} \mathrm{Cl}$ at a mass fraction of chlorobenzene $g=0.0001$ from composition of mixture and various reference temperatures: 1 - $1000 \mathrm{~K}$; 2$1100 \mathrm{~K}$; 3- $1200 \mathrm{~K}$; 4- $1300 \mathrm{~K}$; 5- $1400 \mathrm{~K}$.

Concentration of chloromethane on time grows in temperature range $1000 \ldots 1400 \mathrm{~K}$ with different intensity depending on the level of temperature (fig. 4).

Mole dole of the most reactionary and active atom of hydrogen and the radical $\mathrm{OH}$ at the necessary temperatures remain approximately constant, and with a growth of temperature sharply fall (fig. 5,6).

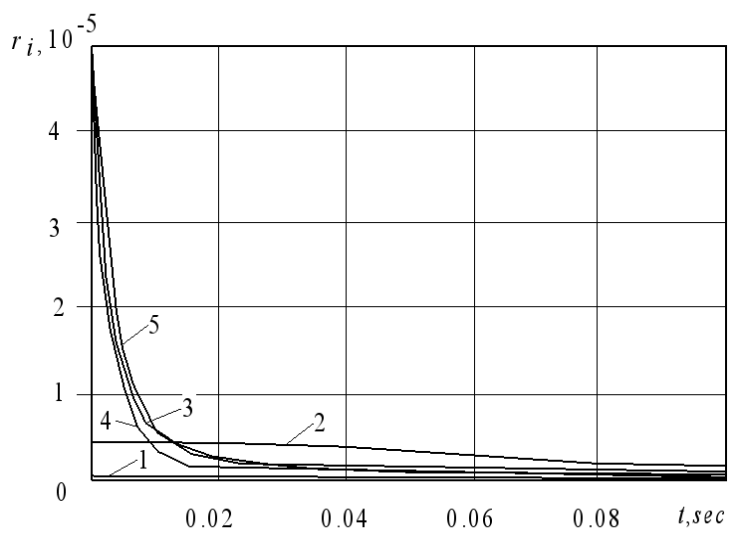

Fig. 5. Change of a mole dole atomic hydrogen $H$ at a mass fraction of chlorobenzene $g=0.0001$ from composition of mixture and various reference temperatures: 1 - $1000 \mathrm{~K} ; 2$ $1100 \mathrm{~K}$; 3- $1200 \mathrm{~K}$; 4- $1300 \mathrm{~K}$; 5- $1400 \mathrm{~K}$.

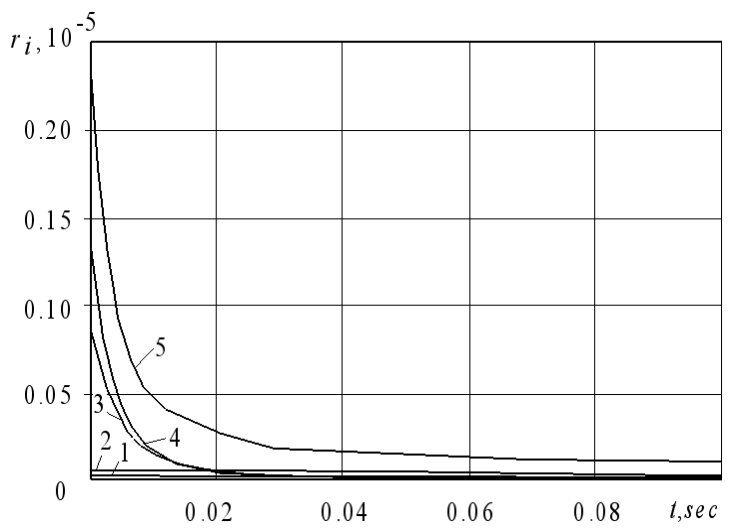

Fig. 6. Change of a mole dole $\mathrm{OH}$ at a mass fraction of chlorobenzene $g=0.0001$ from composition of mixture and various reference temperatures: $1-1000 \mathrm{~K} ; 2-1100 \mathrm{~K} ; 3-1200$ $\mathrm{K} ; 4-1300 \mathrm{~K}$; 5- $1400 \mathrm{~K}$.
Results of the second computing experiment, which show changes of molar concentration of chlorinecontaining connections depending on temperature and a mass fraction of products of decomposition of highenergy chemical fuels, are given in fig. 7-9.

The received results meet physical expectations of conversion of chemical fuels and the gas-phase mechanism of chemical reactions accepted in calculation. Concentration chlorobenzene and chloromethane on temperature have peak in the range from $1000 \ldots 1300 \mathrm{~K}$ and sharp decrease in a molar share at more high temperature (fig. 7) which is defined by the used mechanism of chemical reactions. Change of concentration $\mathrm{C}_{6} \mathrm{H}_{4} \mathrm{Cl}_{2}$ и $\mathrm{C}_{2} \mathrm{Cl}_{4}$ (fig. 8) is typical, with temperature increase it sharply decreases. Change of other concentration of connections with chlorine $\mathrm{Cl}_{2}$, $\mathrm{ClO}$ is shown in fig. 9. Concentration of chlorine $\mathrm{Cl}_{2}$ has a minimum at a temperature $1000 \mathrm{~K}$ and increases with growth of temperature. Change of concentration $\mathrm{ClO}$ has constant value and begins to increase considerably at high temperatures.

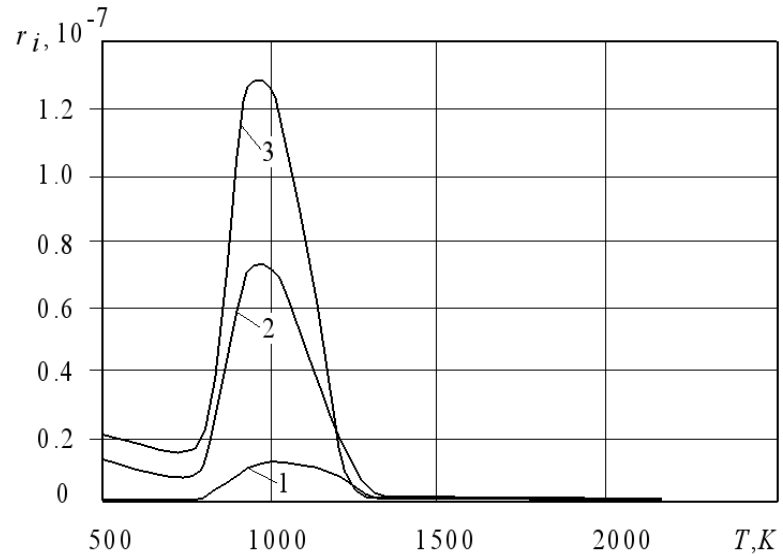

Fig. 7. Change of mole dole of chloromethane depending on temperature and a mass fraction of the brought decomposition products of chemical fuel: $1-g=0.03 ; 2-g=0.04 ; 3-g=0.05$.

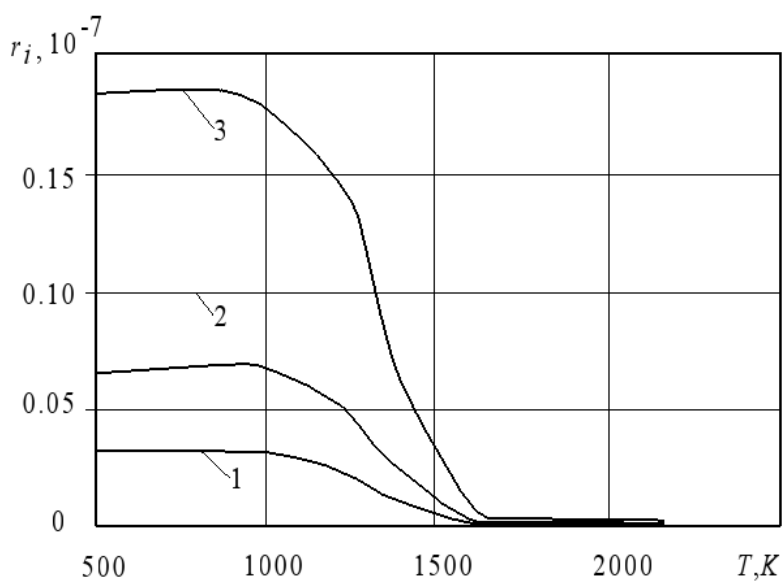

Fig. 8. Change of mole dole of dichlorobenzene depending on temperature and a mass fraction of the brought decomposition products of chemical fuel: $1-g=0.03 ; 2-g=0.04 ; 3-g=0.05$. 


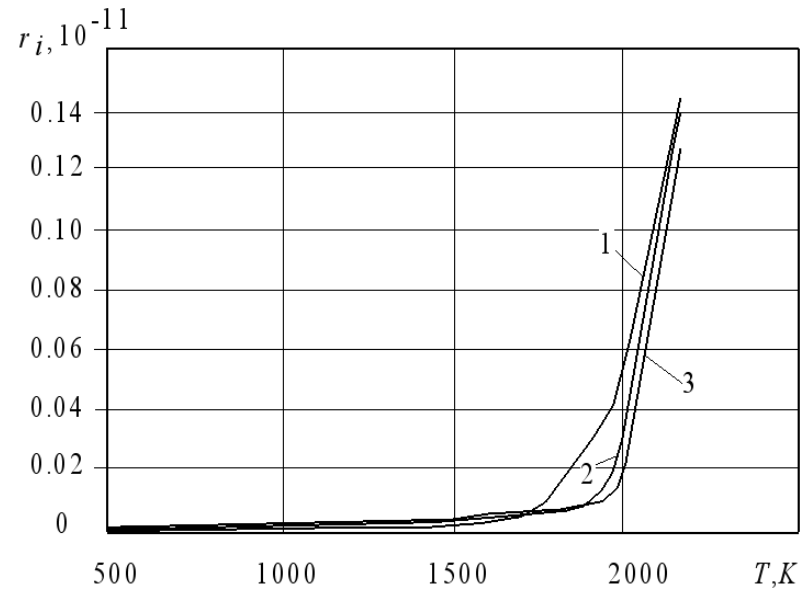

Fig. 9. Change of mole dole of oxide of chlorine depending on temperature and a mass fraction of the brought decomposition products of chemical fuel: $1-g=0.03 ; 2-g=0.04 ; 3-g=0.05$.

Taking into account the made numerical experiments the following recommendations for minimization of emission of dioxins when burning chemical fuels are made:

1. It is offered to study mechanisms of formation of dioxins. It will allow developing a number of the approaches directed to improvement of modern methods of combustion of chemical fuels for the purpose of reduction of an output of dioxins.

2. It is offered to carry out the improvement of the organization of process of burning leading to the fullest combustion and, therefore, reduction of concentration of organic molecules and sooty particles. Without availability of organic substances at temperatures of $500 \ldots 800 \mathrm{~K}$ dioxins is not formed. Other factor influencing the increased output, dioxins existence of the condensed (cindery) particles of a certain structure is. Reduction of their output will promote decrease in emission of dioxins.

3 . It is offered to carry out the technological process based on a thermochemical method of conversion of complex chemicals and their mixtures at high temperatures $(\sim 2500 \ldots 3000 \mathrm{~K})$ with the subsequent sharp decrease in temperature to values $\mathrm{T}<450 \mathrm{~K}$, causing "freezing" of high-temperature products of reactions. In a high-temperature zone dioxins is not formed. In a lowtemperature zone, the formation of secondary dioxins is complicated because of low speeds of chemical reactions. Sharp decrease in temperature can be carried out or expansion of combustion products in nozzles to the speeds coming to sound or introduction to hightemperature products of reactions of water or salt solutions.

4. Alternative method is adding of additives to off gases, which inhibit the superficial reactions responsible for formation of dioxins. As such, additives it is possible to use trimethylamine, oxide of calcium and connection are gray as these connections or products of their disintegration interfere with transformation of pentachlorophenol into dioxins. In particular, sulfur dioxide introduction can be perspective $\mathrm{SO}_{2}$.

\section{Conclusions}

Results of settlement researches showed that process of education and decomposition of the precursors of the dioxins in combustion products of chemical fuels is significantly disequilibrium.

Based on the analysis of the available data on mechanisms of speeds of chemical reactions of transformations of chlorine-containing connections the possible kinetic models of processes in combustion chambers allowing describing qualitatively dynamics of decomposition of the precursors of the dioxins, which are a part of products of burning of chemical fuels, are formed.

Possible ways of minimization of emission of dioxins at combustion of chemical fuels are represented.

\section{References}

1. D. Li, H.-Q. Xu, L. Jiao, and H.-L. Jiang, EnergyChem (2019)

2. X. Wang, Z. Hu, G. Wang, X. Luo, R. Ruan, Q. Jin, and H. Tan, J. Energy Inst. (2019)

3. S. O. Ajayi, L. O. Oyedele, M. Bilal, O. O. Akinade, H. A. Alaka, H. A. Owolabi, and K. O. Kadiri, Resour. Conserv. Recycl. (2015)

4. A. J. Ridout, M. Carrier, and J. Görgens, J. Anal. Appl. Pyrolysis (2015)

5. J. V. Jayarama Krishna, O. P. Korobeinichev, and R. Vinu, J. Anal. Appl. Pyrolysis (2019)

6. H. Wu, J. Zuo, H. Yuan, G. Zillante, and J. Wang, Resour. Conserv. Recycl. (2019)

7. K. Duanguppama, N. Suwapaet, and A. Pattiya, J. Anal. Appl. Pyrolysis (2016)

8. I. Muise, M. Adams, R. Côté, and G. W. Price, Resour. Conserv. Recycl. (2016)

9. L. M. Sarmiento, K. A. Clavier, J. M. Paris, C. C. Ferraro, and T. G. Townsend, Resour. Conserv. Recycl. (2019)

10. J. Xiao, F. Li, Q. Zhong, J. Huang, B. Wang, and Y. Zhang, J. Anal. Appl. Pyrolysis (2016)

11. G. Chen, X. Ma, M. Lin, X. Peng, and Z. Yu, J. Energy Inst. (2016)

12. P. Chaudhari, B. Ravi, P. Bagaria, and C. Mashuga, Process Saf. Environ. Prot. (2019)

13. R. Miandad, M. A. Barakat, A. S. Aburiazaiza, M. Rehan, and A. S. Nizami, Process Saf. Environ. Prot. (2016)

14. S. Wu, S. Huang, Y. Wu, and J. Gao, J. Energy Inst. (2015)

15. Y. Liu, P. Xing, and J. Liu, Resour. Conserv. Recycl. (2017)

16. K. Singh and J. Zondlo, J. Energy Inst. (2017)

17. K. Barbakadze, W. Brostow, G. Granowski, N. Hnatchuk, S. Lohse, and A. T. Osmanson, Resour. Conserv. Recycl. (2018)

18. A. Shehzad, M. J. K. Bashir, S. Sethupathi, and J. W. Lim, Process Saf. Environ. Prot. (2015)

19. Y. Li, S. Huang, Y. Wu, S. Wu, and J. Gao, J. Energy Inst. (2019)

20. F. Du and K. Wang, Process Saf. Environ. Prot. 
(2019)

21. V.E. Alemasov, A.F. Dregalin, A.S. Cherenkov. Bases of the theory of physical and chemical processes in heat engines and power stations. - M.: Chemistry, 2000. - $520 \mathrm{p}$.

22. Dorofeeva, Iorish, Moiseeva J. Chem. Eng. Data (1999) 44. pp. 516-523.

23. V.G. Kryukov and other. Burning and a current in units of power stations: modeling, power, ecology. M.: Janus, 1997. 